\title{
Do endosonographers agree on the presence of bile duct sludge and the subsequent need for intervention?
}

\section{다 (용}

\section{Authors}

Rutger Quispel ${ }^{*, 1}$, Hannah M. Schutz ${ }^{*, 1}$, Nora D. Hallensleben², Abha Bhalla ${ }^{3}$, Robin Timmer ${ }^{4}$, Jeanin E. van Hooft ${ }^{5,6}$, Niels G. Venneman ${ }^{7}$, Nicole S. Erler ${ }^{8}$, Bart J. Veldt' ${ }^{1}$, Lydi M.J.W. van Driel ${ }^{9}$, Marco J. Bruno ${ }^{9}$

Institutions

1 Department of Gastroenterology and Hepatology, Reinier de Graaf Hospital, Delft, Netherlands

2 Department of Gastroenterology and Hepatology, Erasmus University Medical Center, Rotterdam, Netherlands

3 Department of Gastroenterology and Hepatology, HAGA Hospital, Den Haag, Netherlands

4 Department of Gastroenterology and Hepatology, St. Antonius Hospital, Nieuwegein, Netherlands

5 Department of Gastroenterology and Hepatology, Academic Medical Center, Amsterdam, Netherlands

6 Department of Gastroenterology and Hepatology, Leiden University Medical Center Leiden, Netherlands

7 Department of Gastroenterology and Hepatology, Medisch Spectrum Twente, Enschede, Netherlands

8 Department of Biostatistics, Erasmus University Medical Center, Rotterdam, Netherlands

9 Department of Gastroenterology and Hepatology, Erasmus University Medical Center, Rotterdam, Netherlands

submitted 25.9.2020

accepted after revision 20.1.2021

\section{Bibliography}

Endosc Int Open 2021; 09: E911-E917

DOI 10.1055/a-1452-8919

ISSN 2364-3722

(C) 2021. The Author(s).

This is an open access article published by Thieme under the terms of the Creative Commons Attribution-NonDerivative-NonCommercial License, permitting copying and reproduction so long as the original work is given appropriate credit. Contents may not be used for commercial purposes, or adapted, remixed, transformed or built upon. (https://creativecommons.org/licenses/by-nc-nd/4.0/)

Georg Thieme Verlag KG, Rüdigerstraße 14,

70469 Stuttgart, Germany

Corresponding author

Rutger Quispel, Reinier de Graaf Gasthuis - Gastroenterology and Hepatology, Reinier de Graafweg 5 2625AD Delft Zuid Holland 2625AD, Netherlands
Fax: +31152609111

r.quispel@rdgg.nl

\# Supplementary material is available under https://doi.org/10.1055/a-1452-8919

\section{ABSTRACT}

Background and study aims Endoscopic ultrasonography (EUS) is a tool widely used to diagnose bile duct lithiasis. In approximately one out of five patients with positive findings at EUS, sludge is detected in the bile duct instead of stones. The objective of this study was to establish the agreement among endosonographers regarding: 1. presence of common bile duct (CBD) stones, microlithiasis and sludge; and 2. the need for subsequent treatment.

Patients and methods 30 EUS videos of patients with an intermediate probability of CBD stones were evaluated by 41 endosonographers. Experience in EUS and endoscopic retrograde cholangiopancreatography, and the endosonographers' type of practices were recorded. Fleiss' kappa statistics were used to quantify the agreement. Associations between levels of experience and both EUS ratings and treatment decisions were investigated using mixed effects models.

Results A total of 1230 ratings and treatment decisions were evaluated. The overall agreement on EUS findings was fair (Fleiss' $\mathrm{k}$ 0.32). The agreement on presence of stones was moderate $(\kappa 0.46)$. For microlithiasis it was fair ( $\kappa 0.25$ ) and for sludge it was slight ( $\mathrm{0} 0.16$ ). In cases with $\mathrm{CBD}$ stones there was an almost perfect agreement for the decision to subsequently perform an ERC+ES.In case of presumed microlithiasis or sludge an ERC was opted for in $78 \%$ and $51 \%$ of cases, respectively. Differences in experience and types of practice appear unrelated to the agreement on both EUS findings and the decision for subsequent treatment.

Conclusions There is only slight agreement among endosonographers regarding the presence of bile duct sludge. Regarding the need for subsequent treatment of bile duct sludge there is no consensus.

\footnotetext{
* These authors contributed equally
} 


\section{Introduction}

In patients with suspected bile duct stones, endoscopic ultrasonography (EUS) is an excellent tool to prevent unnecessary endoscopic retrograde cholangiography (ERC) with endoscopic sphincterotomy (ES) and its complications. EUS in patients with suspected bile duct stones rules out the presence of bile duct stones in up to $65 \%$ of patients [1,2]. In patients without cholangitis, the 2019 ESGE guideline on endoscopic management of common bile duct (CBD) stones recommends to proceed to $E R C+E S$ only when CBD stones are proven on imaging modalities that have a high specificity [3].

In approximately one out of five patients with positive findings at EUS performed for this indication, bile duct sludge is detected instead of stones [4,5]. Sludge is an ultrasound diagnosis usually described as layered, mobile, low-amplitude echoes without shadowing occurring in either the gallbladder and/or bile ducts [6, 7]. Studies comparing EUS and microscopic examination of bile concluded that sludge represents bile precipitate out of solution $[8,9]$. Usually this precipitate consists of cholesterol monohydrate crystals, calcium bilirubinate granules and other calcium salts. Sludge is considered an early and reversible state of bile stone disease only to be treated when causing biliary symptoms $[10,11]$. Gallbladder sludge in symptomatic patients is considered an indication for cholecystectomy.

Sludge and small stones or microlithiasis (defined as stones $<3 \mathrm{~mm}$ ) in the CBD, are known to have an increased tendency to pass spontaneously into the bowel in comparison to stones $>3 \mathrm{~mm}[5,12-17]$. They have also been associated with an increased incidence of biliary pancreatitis $[18,19]$. However, because the likelihood of developing biliary complications in patients with bile duct microlithiasis or sludge is currently unknown, it is unclear if detection of sludge or microlithiasis in the bile duct at EUS should prompt for an ERC+ES, or whether a watchful waiting strategy can be adopted.

EUS is a known operator-dependent technique [20]. Moreover, agreement regarding the presence of sludge or microlithiasis on EUS and the potential indication for treatment have not been investigated.

The purpose of the current study was to determine the interobserver agreement among endosonographers regarding the presence or absence of CBD stones, microlithiasis and sludge, and their advice for subsequent treatment. We also evaluated the role of the endosonographers' experience in EUS and/or endoscopic retrograde cholangiopancreatography (ERCP), and the endosonographers' type of practice regarding EUS findings and treatment decisions.

\section{Patients and methods}

\section{Study aims}

The objective of this study was to establish the agreement among endosonographers regarding: 1. presence of CBD stones, microlithiasis and sludge, and 2 . the need for subsequent treatment.

\section{Study design}

The study protocol was approved by the local medical ethics committee (METC Leiden, Den Haag, Delft, Z19.050). Videos of linear EUS procedures of patients ( $>18$ years old) with intermediate probability of bile duct lithiasis, according to the 2010 ASGE criteria [21], were recorded for the purpose of this study.

\section{Video fragments}

Videos were digitally recorded by 5 different endosonographers from different hospitals using linear EUS-endoscopes (GF-UCT 180 or GF-UCT 260, Olympus, Leiderdorp, the Netherlands) and different processors (Aloka F75, Aloka $\alpha 10$ or Aloka $\alpha 7$, Hitachi Medical Systems B.V., Reeuwijk, the Netherlands). All recording endosonographers had more than 10 years of clinical experience performing and teaching EUS. Aiming for a significant proportion of invited endosonographers to comply with our protocol and complete the evaluation we chose to limit the number of video fragments to 30 and the length of the fragments to 30 seconds. Fifteen EUS video fragments were filmed from the duodenal bulb, and 15 from the descending duodenum. Videos were edited by one endosonographer using Movavi video editor plus, version 15.4.0 (Movavi Software Limited, Limassol, Cyprus). Video fragments were presented in the best possible video-format (mp4-files, framesize 1920x1080, speed 30 frames/sec) incorporated in a web-based survey using Castor v2020.1.16 (Castor EDC, Amsterdam, the Netherlands). None of the endosonographers involved in recording and editing the videos was involved in rating the video fragments for the purpose of this study.

\section{Endosonographers}

Endosonographers in the Netherlands are all formally trained in endosonography for at least a year at a referral center. A total of 113 Endosonographers was invited to participate in this study by e-mail. Of the invited endosonographers 58 did not respond to the invitation, 3 responded not to be willing to participate, and 11 did not finish the survey before the deadline. For each of the 41 participants experience in both EUS and ERCP including the number of years performing these interventions, and number of procedures performed annually, were recorded. Types of practice (tertiary care/community hospital) were also registered.

\section{Evaluation of video fragments}

Each video fragment was rated by each observer independently for the presence or absence of stones, microlithiasis or sludge in the CBD ( $\mathbf{F i g . 1}$ ). Sludge was defined as echoic, cloud shaped and mobile bile duct content, without acoustic shadowing. Microlithiasis was defined as stones $<3 \mathrm{~mm}$ in size with or without acoustic shadowing ( $>$ Table 1 ) [22-24]. The raters were asked whether or not they would proceed to ERC + ES in each case.

The primary endpoint was the interobserver agreement among endosonographers on the presence or absence of CBD stones, microlithiasis or sludge. 

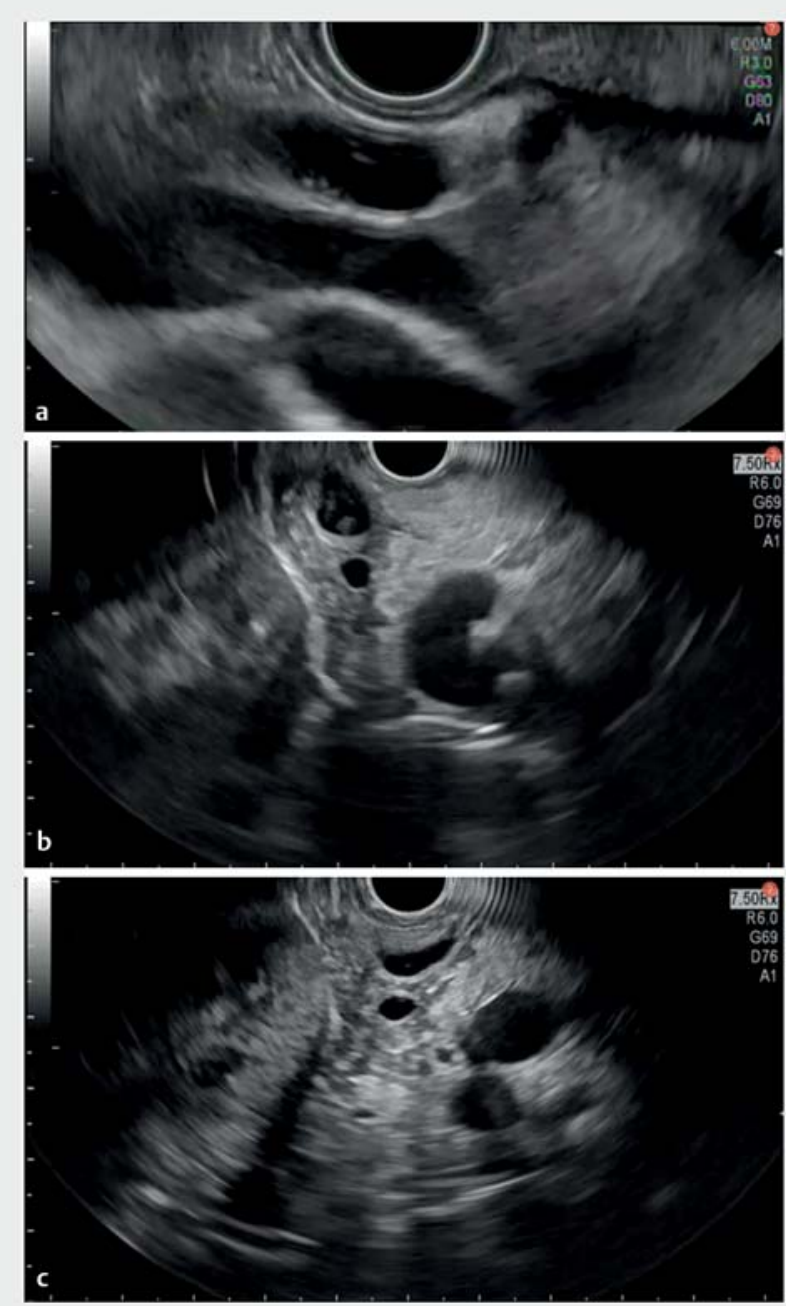

- Fig. 1 Images of evaluated EUS videos. Microlithiasis, sludge or artifact?

Secondary endpoints were the interobserver agreement on the need for ERC + ES (yes/no) and differences in interobserver agreement between experts and non-experts.

\section{Statistics}

The analyses were performed using $R$ version 4.0.2 (2020-0622) ( $R$ Core Team 2020). Assuming that 41 endosonographers would evaluate 30 videos, and that the prevalence of various EUS diagnoses would be "clean" (50\%), "sludge” (15\%), “microlithiasis" (5\%), or "one or more stones" (30\%), we performed a power calculation using simulation. A total of 500 datasets was generated with varying values of agreement from which Fleiss' $\mathrm{k}$ and corresponding $95 \%$ confidence intervals were calculated. The resulting estimates are shown in Fig. $\mathbf{1 a}$ and Table 1a (Appendix). To approximate the values of the lower and upper bounds of the $95 \%$ confidence interval for any given k-value, linear regression models were fitted in which the non-linear association with the corresponding $\mathrm{K}$-value was modeled using natural cubic splines with 3 degrees of freedom. The fitted values
Table 1 EUS definitions of various presentations of bile duct lithiasis.

\begin{tabular}{|l|l|}
\hline & Definition \\
\hline Sludge & $\begin{array}{l}\text { Layered, cloud shaped, mobile echoic bile duct content, } \\
\text { without acoustic shadowing }\end{array}$ \\
\hline Microli- & $\begin{array}{l}\text { Hyperechoic circumscript bile duct content, } \\
<3 \text { mm with or without acoustic shadowing }\end{array}$ \\
\hline thiasis & $\begin{array}{l}\text { Hyperechoic circumscript bile duct content, } \\
\geq 3 \text { mm with or without acoustic shadowing }\end{array}$ \\
\hline Stone(s) & $\begin{array}{l}\text { References: [21-23] } \\
\text { EUS, endoscopic ultrasonography. }\end{array}$ \\
\hline
\end{tabular}

show that for slight agreement (к 0.1 ), the $95 \%$ confidence interval can be expected to range from approximately 0.05 to 0.15 , and that for moderate agreement ( $\mathrm{\kappa} 0.4$ ) the corresponding $95 \%$ confidence interval is expected to range from approximately 0.27 to 0.53 .

Characteristics of the participating raters were summarized using medians and ranges or counts and proportions, as appropriate.

Multirater Fleiss' k-values were calculated to quantify the agreement between raters. K-statistics were interpreted based on the convention by Landis and Koch, and compared with a two-sided paired t-test with level $\alpha=0.05$, using the "linearization method" proposed by Gwet et al. $[25,26]$. The linearity correction is necessary since most agreement coefficients are not linear statistics which is a requirement for the standard ttest.

To estimate the expected proportion of videos for which an endoscopist would advise ERC $+E S$, while taking into account the correlation between the evaluations of multiple videos by the same endoscopist, we fitted a logistic mixed model for the advice of ERC +ES depending on the diagnosis and included endoscopist specific (random) effects for the intercept and diagnosis [27].

Associations between levels of experience and either the diagnosis of "sludge" or the advice for subsequent ERC+ES were investigated using logistic mixed effects models, that use the experience level as fixed effect covariate and take into account the correlation between repeated measurements within endoscopists (i. e., the same endoscopist scoring multiple videos) by including an endoscopist specific (random) intercept. The results are marginalized using the technique described by Hedeker et al., as implemented in the R package GLMMadaptive and can be interpreted on the population level $[28,29]$.

\section{Results}

\section{Endosonographers and their experience}

The web-based survey and evaluation of the 30 EUS video fragments was completed by 41 endosonographers. Eight endosonographers (19\%) worked in academic practice and the remaining $33(81 \%)$ in community hospitals (> Table 2 ). Median posttraining EUS experience was 6 years (range 1-25 years) while performing a median of 60 (20-300) procedures annually. The 
Table 2 Endosonographers and their experience.

\begin{tabular}{|l|l|}
\hline Type of practice $(\mathbf{n}=\mathbf{4 1})$ & $\mathbf{n}(\%)$ \\
\hline Academic hospital & $8(19)$ \\
\hline Community hospital & $33(81)$ \\
\hline EUS experience $(\mathbf{n}=41)$ & Median (range) \\
\hline Years & $6(1-25)$ \\
\hline Procedures/year & $60(20-300)$ \\
\hline ERCP experience $(\mathbf{n}=27)$ & Median (range) \\
\hline Years & $10(1-30)$ \\
\hline Procedures/year & $73(30-400)$ \\
\hline $\begin{array}{l}\text { EUS, endoscopic ultrasonography; ERCP, endoscopic retrograde cholangio- } \\
\text { pancreatography. }\end{array}$ \\
\hline
\end{tabular}

majority of endosonographers (27 of 41, 66\%) also performed ERCP procedures, with a median procedural experience of 10 years (range 1-30 years) while performing a median of 73 (20-300) ERCP procedures annually ( $\triangleright$ Table 2$)$.

\section{Interobserver agreement on EUS diagnosis and treatment decisions}

A total of 1230 ratings $(41 \times 30$ video fragments $)$ and 1230 treatment decisions were evaluated. The overall interobserver agreement on EUS findings was fair (Fleiss' $\mathrm{k} 0.32$ ). The agreement on presence or absence of stones was moderate (both $\mathrm{k}$ 0.46 ). For microlithiasis the agreement was fair ( $k 0.25$ ) and for sludge there was slight agreement (к 0.16) ( $>$ Table 3).

In 803 out of 1230 cases (65\%) the evaluation of an EUS video fragment led to the advice not to proceed to ERC+ES. The overall interobserver agreement to proceed to ERC+ES was moderate ( $\mathrm{k} 0.41,95 \% \mathrm{Cl}$ [0.25-0.55]). In cases with CBD stones or with a "clean" CBD there was almost perfect agreement for the decision to subsequently perform an ERC +ES or
Table 3 Ratings, interobserver agreement, and advice about treatment.

\begin{tabular}{|l|r|r|r|r|}
\hline $\begin{array}{l}\text { EUS diagno- } \\
\text { sis }\end{array}$ & $\mathbf{n}$ & Fleiss' $\mathbf{~ ( 9 5 \% C l )}$ & \multicolumn{2}{|c|}{ Advice about ERCP } \\
\hline Clean CBD & 646 & $0.46(0.32-0.60)$ & $1(0)$ & 645 \\
\hline Sludge & 235 & $0.16(0.07-0.25)$ & $120(51)$ & 115 \\
\hline Microlithiasis & 194 & $0.25(0.07-0.43)$ & $152(78)$ & 42 \\
\hline $\begin{array}{l}\text { One or more } \\
\text { stone(s) }\end{array}$ & 155 & $0.46(0.13-0.78)$ & $154(99)$ & 1 \\
\hline Overall & 1230 & $0.35(0.21-0.48)$ & $427(35)$ & 803 \\
\hline
\end{tabular}

EUS, endoscopic ultrasonography; CBD, common bile duct.

not. In patients with presumed microlithiasis or sludge it was chosen to perform ERC +ES in $78 \%$ and $51 \%$ of cases, respectively ( $\triangleright$ Table 3 ).

In cases where microlithiasis was diagnosed the advice to proceed to ERC + ES ranged from $20 \%$ to $100 \%$ among endosonographers. When sludge was diagnosed the advice to proceed to $E R C+E S$ ranged from $0 \%$ to $100 \%$. Seven of 41 raters (17\%) always advised against ERC+ES, and 13 raters (32\%) always advised to proceed to ERC+ES in these cases ( $\triangleright$ Fig. 2 and - Fig. 3).

\section{Experience and interobserver agreement}

Agreement for EUS diagnosis among academic hospital endosonographers was fair ( $\mathrm{k} 0.32,95 \% \mathrm{Cl}[0.16-0.48]$ ) as was agreement among community hospitals endosonographers ( $\mathrm{K}$ $0.32,95 \% \mathrm{Cl}[0.20-0.43])$. For the advice to proceed to ERC+ ES there was moderate agreement amongst both academic and community hospital endosonographers, $\mathrm{k} 0.41,95 \% \mathrm{Cl}$ [0.23-0.59] vs $\mathrm{k} 0.40,95 \% \mathrm{Cl}[0.25-0.55]$ respectively.
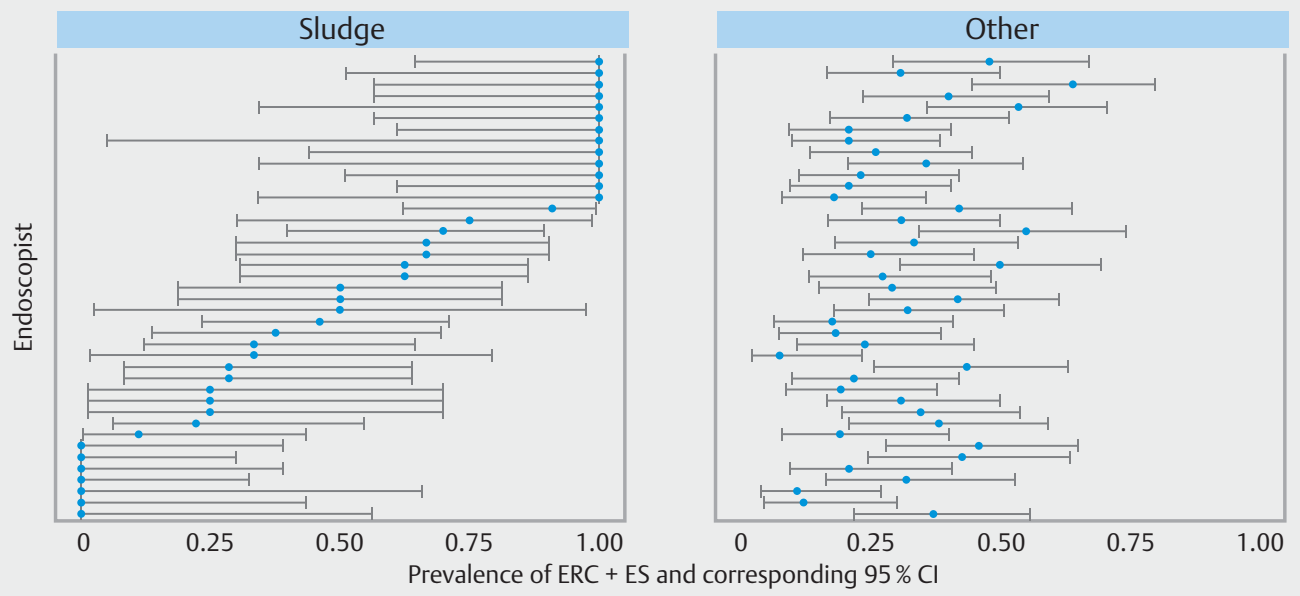

Fig. 2 Proportion of videos for which ERCP was advised per endoscopists by EUS diagnosis (sludge vs. other). 


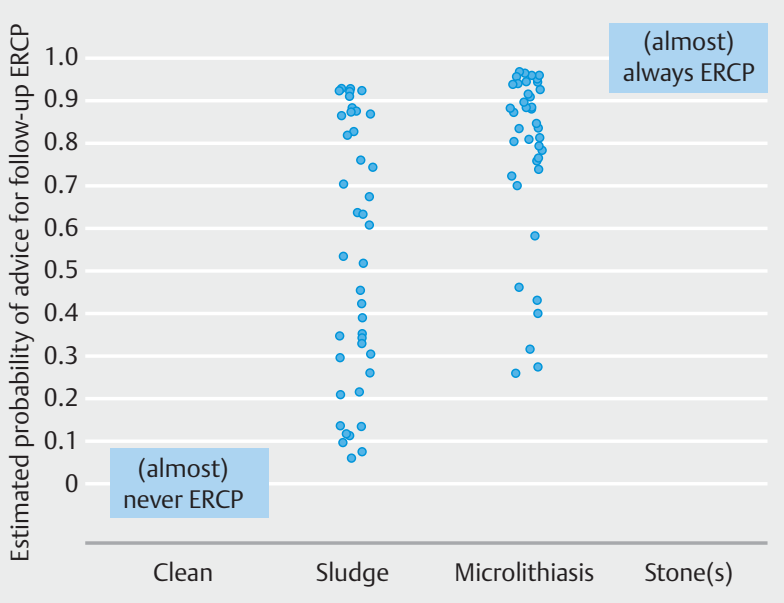

- Fig. 3 Estimated probability of advice to proceed with ERCP per endosonographer per diagnosis.

There was no evidence for an association between differences in EUS experience (either in years or in number of procedures performed annually) and the proportion of sludge diagnoses ( $\vee$ Table 4 ). There was no significant association between the advice to proceed to ERC + ES and whether or not the endosonographer performs ERCPs him- or herself, ERCP experience in years, or number of ERCPs performed annually.

\section{Endoscope position and interobserver agreement}

The agreement on EUS diagnosis of video fragments recorded from both the duodenal bulb and the descending duodenum was fair ( $\mathrm{k} 0.36,95 \% \mathrm{Cl}[0.17-0.56]$ and $\mathrm{\kappa} 0.28,95 \% \mathrm{Cl}$ [0.140.43 ] respectively). There was no significant difference in agreement regarding videos from different scope positions $(P$ $=0.50)$.

\section{Discussion}

Endosonography plays a pivotal role in selecting patients with suspected bile duct lithiasis for ERC + ES. However, interobserver agreement among endosonographers regarding presence of CBD stones, which was the primary endpoint of this study, was only moderate. Moreover, there was only slight interobserver agreement among endosonographers regarding presence of microlithiasis and sludge, the second primary endpoint.

In cases with either stones or a clean bile duct there was an almost perfect agreement to either proceed to or refrain from $\mathrm{ERC}+\mathrm{ES}$. In cases with microlithiasis or sludge in the bile duct there was no consensus about the need for subsequent ERC+ ES. There was no evidence for a relation between differences in experience in both EUS and/or ERC+ES, types of practice, and agreement on both EUS findings and the decision for subsequent treatment.

This was the first study to evaluate interobserver agreement of endosonographers rating EUS video fragments of patients with suspected bile duct lithiasis. Although interobserver agreement on gallbladder sludge is probably better than the only slight agreement among endosonographers on the presence of sludge in de CBD, the findings of this study shed a different light on previous publications regarding the finding of sludge (in gallbladder and/or CBD) at EUS.

Sludge accounts for $20 \%$ to $25 \%$ of the abnormalities detected in the CBD at EUS in patients with suspected bile duct lithiasis $[4,5]$. This estimate is based on two retrospective studies only and may be an overestimation of the true prevalence. Biliary sludge is detected in up to $75 \%$ of patients with idiopathic pancreatitis at EUS in patients with their gallbladder in situ. In idiopathic pancreatitis in postcholecystectomy patients CBD sludge is detected in $10 \%$ to $15 \%$ of cases [30]. In these patients initially suspected to have suffered from idiopathic pancreatitis the diagnosis of sludge in the CBD is relevant since it is considered an indication for cholecystectomy and ERC+ES respectively [31, 32]. In the current study comprising of patients with an intermediate probability of gallstones but not having suffered from pancreatitis, ERC + ES was considered not indicated by the endosonographer in $65 \%$ of the cases. This proportion is similar to the findings of two meta-analyses studying the role of EUS in patients with suspected bile duct lithiasis in clinical practice [1,2].

Strengths of the current study are the substantial number of endosonographers involved when compared to previously published EUS interobserver studies on chronic pancreatitis, find-

\begin{tabular}{|c|c|c|c|}
\hline EUS experience and sludge diagnosis $(n=41)$ & OR & $P$ value & $95 \% \mathrm{Cl}$ \\
\hline Years of experience in EUS & 0.99 & 0.66 & $0.96-1.03$ \\
\hline EUS procedures/year & 1.01 & 0.38 & $0.98-1.04$ \\
\hline Advise to proceed to ERCP $(n=41)$ & OR & $P$ value & $95 \% \mathrm{Cl}$ \\
\hline ERCP performers vs non-performers & 1.26 & 0.23 & $0.87-1.8$ \\
\hline ERCP experience and advice to proceed to ERCP $(n=27)$ & OR & $P$ value & $95 \% \mathrm{Cl}$ \\
\hline Years of experience in ERCP & 0.99 & 0.96 & $0.96-1.04$ \\
\hline ERCP procedures/year & 0.99 & 0.74 & $0.96-1.03$ \\
\hline
\end{tabular}


ings in familial pancreatic cancer kindred's and pancreatic cysts [33-36]. The 41 contributing endosonographers from 27 different hospitals represent approximately $25 \%$ of the total number of endosonographers in the Netherlands. The results of our study therefore signify a rational representation of how findings of biliary sludge are diagnosed and interpreted throughout the Netherlands.

Limitations of our study are the fact that 30 -second video fragments were used. Having a second look when in doubt means playing the video again, which is very different from repositioning the endoscope to confirm or reject a potential diagnosis from another angle.

The only moderate agreement on the presence or absence of bile duct stones is likely to be a reflection of the known operator dependency of EUS [37]. Not only have learning curves of advanced endoscopy trainees proven to be highly variable in prospective studies [38,39], good or even excellent interobserver agreements are rarely found in studies on interobserver variability in EUS [33-36].

Improving interobserver agreement of EUS in patients with suspected bile duct lithiasis starts with basic knowledge regarding the limitations of EUS imaging and potential pitfalls of image interpretation and "tricks" to overcome this. All this should be taught as part of a formal training program learning EUS. Evaluation of the CBD with a linear EUS scope requires careful tracing of the CBD from the liver hilum all the way down to the ampulla by means of different scope positions. It may be difficult to distinguish sludge from EUS imaging artifacts caused by, for example the cystic duct junction or the crossing of vessels, especially in a non-dilated duct and/or a non-stable position of the endoscope. Side-lobe artifacts, offaxis secondary projections of the ultrasound beam, can be misinterpreted as sludge [40]. Repositioning the transducer can cause these artifacts to disappear. Adherence to the simple rule that "when a EUS finding cannot be reproduced it does not exist", prevents a lot of over interpretation and false positive findings.

Knowledge regarding the natural behavior of bile duct stones is limited. The Swedish Gallriks study describes an increased likelihood of biliary complications (biliary pancreatitis, cholangitis or bile duct obstruction) of up to $25 \%$ during a follow-up of 4 years after cholecystectomy when leaving bile duct stones in situ, in comparison to a likelihood of $13 \%$ of complications after clearance of the bile duct (Odds Ratio [OR] 0.44, $95 \% \mathrm{Cl} 0.35-0.55)$ [41]. This justifies performing ERC + ES in all patients with bile duct stones, regardless of the risk of complications [3]. However, the advantage of an intervention aiming to remove bile duct stones is less clear in stones $<4 \mathrm{~mm}$, which may be related to the increased possibility of spontaneous passage into the bowel. Although bile duct sludge is increasingly detected with the growing use of EUS in recent years, its natural behavior is currently unknown. To answer the question whether the EUS findings CBD sludge and microlithiasis in patients with an intermediate probability of bile duct stones justify a subsequent ERC+ES, or that a watchful waiting strategy can be adopted, further studies are needed.

\section{Conclusions}

In summary, our study demonstrates that there is moderate interobserver agreement regarding presence or absence of bile duct stones, and only limited agreement regarding the presence of CBD sludge and microlithiasis among endosonographers. In cases with either sludge or microlithiasis in the bile duct at EUS, there is a lack of consensus whether a subsequent $E R C+E S$ should be performed. Agreement regarding EUS findings or treatment decisions appear unrelated to experience of the rating endosonographer. To guide clinicians and prevent potentially unnecessary ERC + ES, further research into the reliability of an EUS diagnosis of biliary sludge and the need for intervention is indicated.

\section{Acknowledgements}

The authors thank Y. Alderlieste, M.P.G.F. Anten, D. van Asseldonk, J.Bergmann, T. Bisseling, M. Bigirwamungu-Bargeman, K. Boparai, K. van Boxtel, M.P.J. van den Broek, P. Dura, B. van Eijck, C. Fitzpatrick, P. Fockens, C. Hoge, L. Hol, P. Honkoop, A. Inderson, K. S. Korkmaz, M. Ledeboer, I. Leeuwenbugh, A.U.G. van Lent, R. Meiland, S. Mulder, M. Neerincx, S.L. Onderwater, L. Perk, H.J.M. Pullens, J. W. Poley, R. De Ridder, T.C.J. Seerden, B.M.W. Spanier, M. Stolk, A. Thijssen, B.J. Veldt, R. Verburg, R. Verdonk, F. van Vilsteren, R. Voermans, J.M. Vrolijk, M.H. Wobbes and S. Zweers for their efforts in evaluating videos in this study.

\section{Competing interests}

The authors declare that they have no conflict of interest.

References

[1] Petrov MS, Savides TJ. Systematic review of endoscopic ultrasonography versus endoscopic retrograde cholangiopancreatography for suspected choledocholithiasis. Br J Surg 2009; 96: 967-974

[2] Tse F, Liu L, Barkun AN et al. EUS: a meta-analysis of test performance in suspected choledocholithiasis. Gastrointest Endosc 2008; 67: 235244

[3] Manes G, Paspatis G, Aabakken L et al. Endoscopic management of common bile duct stones: European Society of Gastrointestinal Endoscopy (ESGE) guideline. Endoscopy 2019; 51: 472-491

[4] Fusaroli P, Lisotti A, Syguda A et al. Reliability of endoscopic ultrasound in predicting the number and size of common bile duct stones before endoscopic retrograde cholangiopancreatography. Dig Liver Dis 2016; 48: 277-282

[5] Quispel R, van Driel LM, Veldt BJ et al. The utility and yield of endoscopic ultrasonography for suspected choledocholithiasis in common gastroenterology practice. Eur J Gastroenterol Hepatol 2016; 28: 1473-1476

[6] Lee SP. Pathogenesis of biliary sludge. Hepatology 1990; 12: 200S203S; discussion 203S-205S

[7] Lee SP, Maher K, Nicholls JF. Origin and fate of biliary sludge. Gastroenterology 1988; 94: 170-176

[8] Dahan P, Andant C, Levy P et al. Prospective evaluation of endoscopic ultrasonography and microscopic examination of duodenal bile in the 
diagnosis of cholecystolithiasis in 45 patients with normal conventional ultrasonography. Gut 1996; 38: 277-281

[9] Dill JE, Hill S, Callis J et al. Combined endoscopic ultrasound and stimulated biliary drainage in the diagnosis of cholecystitis and microlithiasis. Endoscopy 1995; 27: 218

[10] Keizman D, Ish-Shalom M, Konikoff FM. The clinical significance of bile duct sludge: is it different from bile duct stones? Surg Endosc 2007; 21: 769-773

[11] Ko CW, Sekijima JH, Lee SP. Biliary sludge. Ann Intern Med 1999; 130: 301-311

[12] Collins C, Maguire D, Ireland A et al. A prospective study of common bile duct calculi in patients undergoing laparoscopic cholecystectomy: natural history of choledocholithiasis revisited. Ann Surg 2004; 239: $28-33$

[13] Frossard JL, Hadengue A, Amouyal G et al. Choledocholithiasis: a prospective study of spontaneous common bile duct stone migration. Gastrointest Endosc 2000; 51: 175-179

[14] Hauer-Jensen M, Karesen R, Nygaard K et al. Prospective randomized study of routine intraoperative cholangiography during open cholecystectomy: long-term follow-up and multivariate analysis of predictors of choledocholithiasis. Surgery 1993; 113: 318-323

[15] Khan OA, Balaji S, Branagan G et al. Randomized clinical trial of routine on-table cholangiography during laparoscopic cholecystectomy. Br J Surg 2011; 98: 362-367

[16] Murison MS, Gartell PC, McGinn FP. Does selective peroperative cholangiography result in missed common bile duct stones? J R Coll Surg Edinb 1993; 38: 220-224

[17] Nies C, Bauknecht F, Groth C et al. [Intraoperative cholangiography as a routine method? A prospective, controlled, randomized study]. Chirurg 1997; 68: 892-897

[18] Diehl AK, Holleman DR Jr, Chapman JB et al. Gallstone size and risk of pancreatitis. Arch Intern Med 1997; 157: 1674-1678

[19] Venneman NG, Buskens E, Besselink MG et al. Small gallstones are associated with increased risk of acute pancreatitis: potential benefits of prophylactic cholecystectomy? Am J Gastroenterol 2005; 100: $2540-2550$

[20] Wani S, Keswani R, Hall M et al. A Prospective multicenter study evaluating learning curves and competence in endoscopic ultrasound and endoscopic retrograde cholangiopancreatography among advanced endoscopy trainees: the rapid assessment of trainee endoscopy skills study. Clin Gastroenterol Hepatol 2017; 15: 1758-1767 e1711

[21] Maple JT, Ben-Menachem T. ASGE Standards of Practice Committee. et al. The role of endoscopy in the evaluation of suspected choledocholithiasis. Gastrointest Endosc 2010; 71: 1-9

[22] Al-Haddad MA. EUS in Bile Duct, Galbladder, and Ampullary Lesions. In: Hawes RH FP, Varadarajulu S. Endosonography 3rd edition. Elsevier Saunders; 2015: 226-255

[23] Jungst C, Kullak-Ublick GA, Jungst D. Gallstone disease: Microlithiasis and sludge. Best Pract Res Clin Gastroenterol 2006; 20: 1053-1062

[24] Shaffer EA. Gallbladder sludge: what is its clinical significance? Curr Gastroenterol Rep 2001; 3: 166-173
[25] Gwet KL. Testing the difference of correlated agreement coefficients for statistical significance. Educ Psychol Meas 2016; 76: 609-637

[26] Landis JR, Koch GG. The measurement of observer agreement for categorical data. Biometrics 1977; 33: 159-174

[27] Molenberghs GVG. Models for Discrete Longitudinal Data. 2006

[28] Hedeker D, du Toit SHC, Demirtas H et al. A note on marginalization of regression parameters from mixed models of binary outcomes. Biometrics 2018; 74: 354-361

[29] Rizopoulos D. GLMMadaptive: Generalized Linear Mixed Models Using Adaptive Gaussian Quadrature. 2020

[30] Somani P, Sunkara T, Sharma M. Role of endoscopic ultrasound in idiopathic pancreatitis. World J Gastroenterol 2017; 23: 6952-6961

[31] Lee SP, Nicholls JF, Park HZ. Biliary sludge as a cause of acute pancreatitis. N Engl J Med 1992; 326: 589-593

[32] Raty S, Pulkkinen J, Nordback I et al. Can laparoscopic cholecystectomy prevent recurrent idiopathic acute pancreatitis? A prospective randomized multicenter trial. Ann Surg 2015; 262: 736-741

[33] de Jong K, Verlaan T, Dijkgraaf MG et al. Interobserver agreement for endosonography in the diagnosis of pancreatic cysts. Endoscopy 2011; 43: 579-584

[34] Stevens T, Lopez R, Adler DG et al. Multicenter comparison of the interobserver agreement of standard EUS scoring and Rosemont classification scoring for diagnosis of chronic pancreatitis. Gastrointest Endosc 2010; 71: 519-526

[35] Topazian M, Enders F, Kimmey M et al. Interobserver agreement for EUS findings in familial pancreatic-cancer kindreds. Gastrointest Endosc 2007; 66: 62-67

[36] Wallace MB, Hawes RH, Durkalski $V$ et al. The reliability of EUS for the diagnosis of chronic pancreatitis: interobserver agreement among experienced endosonographers. Gastrointest Endosc 2001; 53: 294299

[37] Buxbaum JL, Abbas Fehmi SM. ASGE Standards of Pracitce Committee,. et al. ASGE guideline on the role of endoscopy in the evaluation and management of choledocholithiasis. Gastrointest Endosc 2019; 89: 1075-1105 e1015

[38] Wani S, Cote GA, Keswani R et al. Learning curves for EUS by using cumulative sum analysis: implications for American Society for Gastrointestinal Endoscopy recommendations for training. Gastrointest Endosc 2013; 77: 558-565

[39] Wani S, Han S, Simon V et al. Setting minimum standards for training in EUS and ERCP: results from a prospective multicenter study evaluating learning curves and competence among advanced endoscopy trainees. Gastrointest Endosc 2019; 89: 1160-1168 e1169

[40] Hwang JH KT, Kimmey MB. Principles of Ultrasound. In: Endosonography. Elsevier; 2015

[41] Moller M, Gustafsson U, Rasmussen F et al. Natural course vs interventions to clear common bile duct stones: data from the Swedish Registry for Gallstone Surgery and Endoscopic Retrograde Cholangiopancreatography (GallRiks). JAMA Surg 2014; 149: 1008-1013 